\title{
The influence of timing and frequency of adipose-derived mesenchymal stem cell therapy on immunomodulation outcomes after vascularized composite allotransplantation
}

Plock, Jan A ; Schnider, Jonas T ; Schweizer, Riccardo ; Zhang, Wensheng ; Tsuji, Wakako ; Waldner, Matthias ; Solari, Mario G ; Marra, Kacey G ; Rubin, J Peter ; Gorantla, Vijay S

\begin{abstract}
BACKGROUND: Cellular therapies for immunomodulation in vascularized composite allotransplantation (VCA) have gained importance due to their potential for minimization of immunosuppression. Adipose-derived (AD) mesenchymal stem cells (MSCs) especially have shown encouraging potential. We investigated the influence of timing and frequency of AD-MSC treatment on immunologic and graft survival as well as graft vasculopathy outcomes after VCA. METHODS: Lewis rats received full-mismatched Brown Norway rat hindlimb transplants. Recipient animals were assigned to groups receiving donor-derived AD-MSCs (10 cells/animal) either on postoperative day (POD) 1, POD 4, or repeatedly on POD 4, 8, and 15, and compared to untreated controls. RESULTS: Although AD-MSC administration on POD 1 or POD 4, 8, and 15 resulted in 50\% long-term graft acceptance, recipients treated on POD 4, and controls rejected before POD 50. All treated animals revealed peripheral blood chimerism (4 weeks), most pronounced after repetitive cell administration $(12.92 \%$ vs $5.03 \%$ [POD 1$]$ vs $6.31 \%$ [POD 4]; $\mathrm{P}<0.05$; all $\mathrm{P}<0.01$ vs control 1.45\%). Chimerism was associated with the generation of regulatory $\mathrm{T}$ cells (CD4CD25FoxP3). In vitro mixed lymphocyte reactions revealed modulation of the recipient immune response after AD-MSC treatment. Graft arteries at end point revealed significant differences of arterial intimal thickness between rejecting and AD-MSC-treated animals $(\mathrm{P}<0.01)$. CONCLUSIONS: Taken together, our results point to the potential for repetitive AD-MSC administration in improving outcomes after VCA. Future studies are warranted into optimization of the dosing and frequency of AD-MSC therapy, either alone or used in, combination with other cell therapies (such as hematopoietic stem cells or bone marrow-derived MSC or dendritic cells) for optimization of appropriate conditioning or maintenance regimens.
\end{abstract}

DOI: https://doi.org/10.1097/TP.0000000000001498

Posted at the Zurich Open Repository and Archive, University of Zurich

ZORA URL: https://doi.org/10.5167/uzh-133683

Journal Article

Published Version

Originally published at:

Plock, Jan A; Schnider, Jonas T; Schweizer, Riccardo; Zhang, Wensheng; Tsuji, Wakako; Waldner, Matthias; Solari, Mario G; Marra, Kacey G; Rubin, J Peter; Gorantla, Vijay S (2017). The influence of timing and frequency of adipose-derived mesenchymal stem cell therapy on immunomodulation outcomes after vascularized composite allotransplantation. Transplantation, 101(1):e1-e11.

DOI: https://doi.org/10.1097/TP.0000000000001498 


\section{The Influence of Timing and Frequency of Adipose-Derived Mesenchymal Stem Cell Therapy on Immunomodulation Outcomes After Vascularized Composite Allotransplantation}

Jan A. Plock, MD, ${ }^{1,2,3}$ Jonas T. Schnider, MD, ${ }^{1,2}$ Riccardo Schweizer, MD, ${ }^{1,2,3}$ Wensheng Zhang, MD-PhD, ${ }^{1,2}$ Wakako Tsuji, MD-PhD, ${ }^{1,2}$ Matthias Waldner, MD, ${ }^{1,2,3}$ Mario G. Solari, MD, , ${ }^{1,2}$ Kacey G. Marra, PhD, , ,2,4 J. Peter Rubin, MD, ${ }^{1,2,4}$ and Vijay S. Gorantla, MD-PhD ${ }^{1,2}$

Background. Cellular therapies for immunomodulation in vascularized composite allotransplantation (VCA) have gained importance due to their potential for minimization of immunosuppression. Adipose-derived (AD) mesenchymal stem cells (MSCs) especially have shown encouraging potential. We investigated the influence of timing and frequency of AD-MSC treatment on immunologic and graft survival as well as graft vasculopathy outcomes after VCA. Methods. Lewis rats received full-mismatched Brown Norway rat hindlimb transplants. Recipient animals were assigned to groups receiving donor-derived AD-MSCs $\left(10^{6}\right.$ cells/ animal) either on postoperative day (POD) 1, POD 4, or repeatedly on POD 4, 8, and 15, and compared to untreated controls. Results. Although AD-MSC administration on POD 1 or POD 4, 8, and 15 resulted in 50\% long-term graft acceptance, recipients treated on POD 4, and controls rejected before POD 50. All treated animals revealed peripheral blood chimerism (4 weeks), most pronounced after repetitive cell administration (12.92\% vs 5.03\% [POD 1] vs 6.31\% [POD 4]; $P<0.05$; all $P<0.01$ vs control $1.45 \%)$. Chimerism was associated with the generation of regulatory T cells $\left(C D 4^{+} C D 25^{\text {high }} \mathrm{FoxP} 3^{+}\right)$. In vitro mixed lymphocyte reactions revealed modulation of the recipient immune response after AD-MSC treatment. Graft arteries at end point revealed significant differences of arterial intimal thickness between rejecting and AD-MSC-treated animals $(P<0.01)$. Conclusions. Taken together, our results point to the potential for repetitive AD-MSC administration in improving outcomes after VCA. Future studies are warranted into optimization of the dosing and frequency of AD-MSC therapy, either alone or used in, combination with other cell therapies (such as hematopoietic stem cells or bone marrow-derived MSC or dendritic cells) for optimization of appropriate conditioning or maintenance regimens.

(Transplantation 2017;101: e1-e11)

$\vee$ ascularized composite allotransplantation (VCA) is the newest domain of solid organ transplants as defined by the Organ Procurement and Transplant Network Final Rule. $^{1}$ To date, 115 upper extremity, 35 face and other types of VCA such as uterus, abdominal wall, penis, trachea, bone, and joint have been performed worldwide to restore or reconstruct tissue defects that challenge conventional options. Technical feasibility, immunologic, functional, and graft survival outcomes have been promising but the need for lifelong multidrug immunosuppression remains a key obstacle to expansion of clinical VCA. ${ }^{2-7}$ Patient adherence to medications

\footnotetext{
Received 5 April 2016. Revision received 29 August 2016.

Accepted 31 August 2016.

${ }^{1}$ Department of Plastic Surgery, University of Pittsburgh Medical Center (UPMC), Pittsburgh, PA.

${ }^{2}$ McGowan Institute for Regenerative Medicine, University of Pittsburgh, Pittsburgh, PA.

${ }^{3}$ Department of Plastic Surgery and Hand Surgery, University Hospital Zurich (USZ), Zurich, Switzerland.

${ }^{4}$ Department of Bioengineering, University of Pittsburgh, Pittsburgh, PA.

This study was made possible by the generous support of Department of Defense - Congressionally Directed Medical Research Program Grant Funding W81XWH-11-2-0215 - Pl: Vijay Gorantla). In addition, JTS and RS were recipients of Swiss National Science Foundation funding.
}

is key to minimizing the risks of acute or chronic rejection, both of which could lead to graft attrition or loss. ${ }^{8,9}$ However, immunosuppression can lead to life-threatening or life-shortening complications, such as infections, metabolic effects, end organ failure, ${ }^{10-12}$ and malignancies. ${ }^{13}$ These raise ethical questions of the time trade-off for young, otherwise healthy recipients receiving VCA which are mostly nonlife saving transplants unlike other solid organs.

Although true tolerance remains yet unattainable in clinical transplantation, immunomodulatory or tolerogenic cell therapies could be a near-term goal to help reduce dosing

\section{The authors declare no conflicts of interest}

J.A.P., W.Z., and V.S.G. participated in study idea and design. J.A.P., J.T.S., R. S. participated in animal experiments. R.S., W.Z., W.T., and M.W. participated in cell and tissue processing. J.A.P., J.T.S., W.Z., R.S., W.T., M.W., M.G.S., J.P.R., K.G.M., and V.S.G. participated in data analysis and interpretation. J.A.P., R.S., and V.S.G. participated in article writing. J.T.S., W.Z., W.T., M.W., K.G.M., J.A.P., and V.S.G. participated in article revision.

Correspondence: Vijay S. Gorantla, MD, PhD, University of Pittsburgh Medical Center, Pittsburgh, PA. (gorantlavs@upmc.edu); Jan A. Plock, MD, University Hospital Zurich, Zurich, Switzerland. (jan.plock@usz.ch).

Copyright @ 2016 Wolters Kluwer Health, Inc. All rights reserved.

ISSN: 0041-1337/17/10101-e1

DOl: $10.1097 /$ TP.0000000000001498 
or frequency of immunosuppressive drugs, in turn expanding acceptance and clinical feasibility of VCA by improving the risk benefit equipoise of these procedures. ${ }^{14-16}$

The immunomodulatory effects of mesenchymal stromal cells (MSCs) have been demonstrated in autoimmune disorders ${ }^{17,18}$ and experimental models of VCA. ${ }^{15,19-21}$ MSCs lack costimulatory molecules ${ }^{22-24}$ and are thus immune-privileged in vivo. Clinical studies with MSCs confirm safety profiles of both autologous as well as allogeneic MSCs. ${ }^{23,25}$ Key immunomodulatory functionality of MSCs is purported to be due to their paracrine effects ${ }^{23,26-29}$ or induction of regulatory $\mathrm{T}$ $\left(\mathrm{T}_{\text {reg }}\right)$ cells $^{30-32}$ as shown in animal models of VCA. ${ }^{33,34}$

Among MSCs, adipose-derived (AD) MSCs bear the inherent advantage of providing significantly higher cell yields compared to other sources and lower procurement-site morbidity. ${ }^{35,36}$ Additionally, our prior work and other emerging literature evidence lends credence to the higher immunomodulatory and immunosuppressive potential of AD-MSCs compared with their bone marrow (BM)-derived counterparts (BM-MSCs). ${ }^{37-40}$

Current standard of care induction and maintenance therapy in VCA, include antithymocyte globulin and tacrolimus (FK-506). Potential drug or antibody-induced adverse interactions can occur with MSCs, limiting cell viability or function as shown in studies on rodent and human MSCs. ${ }^{41-44}$ It is therefore important to account for the timing of cellular therapies when coupling them with conditioning and maintenance regimens. This is an area that merits further investigation.

In the present study, we investigated the immunomodulatory properties of AD-MSCs in a stringent rodent hindlimb allotransplantation model. In particular, we assessed the effect of timing and dosing frequency of AD-MSC treatment with relevance to the conditioning regimen, focusing on $\mathrm{T}_{\text {reg }}$ induction and function, induction and persistence of donor chimerism, and allograft survival. We also assessed effects of AD-MSCs on chronic graft vasculopathy (GV) after VCA.

\section{MATERIALS AND METHODS}

All experiments were approved by the University of Pittsburgh Institutional Animal Care and Use Committee and were in compliance with Association for Assessment and Accreditation of Laboratory Animal Care guidelines.

\section{Animals}

Six- to eight-week-old male Lewis (LEW) (RT1 ${ }^{1}$, recipient), Brown Norway (BN) $\left(\mathrm{RT}^{\mathrm{n}}{ }^{\mathrm{n}}\right.$, donor), and Wistar Furth (WF, RT1 $1^{\mathrm{u}}$, third party donor) rats weighing 250 to $300 \mathrm{~g}$. (Harlan, Indianapolis, IN) were housed in specific pathogen-free barrier caging at the University of Pittsburgh.

\section{AD-MSC Isolation and Characterization}

AD-MSC were isolated from adipose tissue excised from inguinal fat pads and bilateral epididymes of $\mathrm{BN}$ rats and enzymatically digested with collagenase type II (Worthington Biochemical Corp, Lakewood, NJ) and bovine serum albumin (Millipore, Billerica, MA) in Hanks balanced saline solution (Cellgro Mediatech Inc. Manassas, VA) for 60 minutes at $37^{\circ} \mathrm{C}$ with gentle shaking. The digested tissue was centrifuged at $1000 \mathrm{rpm}$ for 10 minutes. The cellular pellet (stromal vascular fraction) was resuspended in erythrocyte lysis buffer and filtered through sterile gauze. Finally, the stromal vascular fraction was transferred to sterile culture flasks with
Dulbecco modified Eagle medium (Cellgro Mediatech) plus supplemental Ham's F-12 medium (Gibco, Grand Island, NY). After an attachment period of $6 \mathrm{~h}$, nonadherent cells were removed using a phosphate buffered saline (PBS) wash, leaving only the attached AD-MSCs. Cells were cultured in Dulbecco modified Eagle medium/F12 supplemented with 10\% fetal bovine serum (ATLAS Biologicals, Fort Collins, CO), $0.1 \mu \mathrm{M}$ dexamethasone (Sigma-Aldrich, St. Louis, MO), 1\% penicillin-streptomycin (Gibco), and $1.25 \mathrm{mg} / \mathrm{L}$ amphotericin B (Gibco) and expanded in vitro until passage 3.

For surface marker analysis, cells were detached with $0.25 \%$ trypsin solution (Cellgro Mediatech Inc.), washed, and suspended with PBS. Cells were stained with anti-rat CD29, CD73, CD90, and CD45 antibodies. The cells were then analyzed using an LSRII flow cytometer (fluorescenceactivated cell sorting) using FlowJo software (TreeStar Inc., Ashland, OR). AD-MSCs were positive for CD29, CD73, and CD90 markers and negative for CD45 marker.

\section{Antilymphocyte Serum Effects}

Rabbit-anti-rat-lymphocyte polyclonal serum was purchased from Cedarlane (Burlington, Ontario). Naïve LEW rats were treated with antilymphocyte serum (ALS) $(300 \mu \mathrm{L})$ intraperitoneally to assess white blood cell (leucocyte) depletion in vivo. Blood was collected on day 0 (baseline, before injection), $1,3,6$, and 10 after single ALS administration for monitoring leucocyte counts in nontransplanted naive Lewis rats.

\section{Surgical Model}

LEW rats received orthotopic hindlimb transplants from BN donor rats as described in our prior studies. ${ }^{45}$ An isoflurane vaporizer (VetEquip, Inc., Pleasanton, CA) provided gas concentrations at $2 \%$. Both legs of $\mathrm{BN}$ donors were shaved and retrieved through a circumferential skin incision, ligation of epigastric vessels, dissection of femoral vessels, and transection at the level of the inguinal ligament. The leg was then amputated at mid-femoral level. The femoral artery of the allograft was flushed with $5 \mathrm{~mL}$ of cold heparinized Ringer lactate solution and then stored at $4^{\circ} \mathrm{C}$. The amputation of the LEW recipient leg was performed in a similar fashion, with transection of the vessels at a more distal level than the donor. Osteosynthesis was performed using an 18-gauge needle as an intramedullary rod. The sciatic nerve was adapted using 9-0 nylon sutures (Microsurgery Instruments, Inc., Bellaire, TX), and the muscles were sutured with interrupted 4-0 vicryl sutures (Ethicon Inc., Somerville, NJ). Microsurgical anastomosis of the femoral artery was performed with interrupted 11-0 nylon sutures, whereas a polyamide tube (RiverTech Medical, Chattanooga, TN) was used as cuff for the femoral vein as previously reported. ${ }^{46}$

\section{Experimental Protocol}

All recipients were treated with ALS $(300 \mu \mathrm{L}) 4$ days before and 1 day after surgery. Immunosuppression with FK-506 $(0.5 \mathrm{mg} / \mathrm{kg})$ was administered intraperitoneally to all animals on a daily basis from the day of surgery (day 0 ) to postoperative day (POD) 21.

Animals were assigned randomly to the groups. The experimental groups received $1 \times 10^{6} \mathrm{AD}-\mathrm{MSC}$ s suspended in $1 \mathrm{~mL}$ of PBS administered either on POD $1(\mathrm{n}=8)$, POD 4 $(\mathrm{n}=7)$, or repeatedly on POD 4,8 , and $15(\mathrm{n}=8)$. For this purpose, the animals were anesthetized as described above and the cell aliquots were slowly injected through the penile 
vein using a 30-gauge needle. Control animals received no cellular treatment $(n=5)$. After 4 weeks, blood was collected for peripheral chimerism and $\mathrm{T}_{\text {reg }}$ level assessment. Animals were observed on a daily basis for signs of rejection, which was assessed according to clinical VCA rejection grading. ${ }^{47}$ Rejection grade III or long term survival $>120$ days were defined as endpoints. Once an endpoint was reached, animals were sacrificed for tissue sampling. Lymphatic organs and peripheral blood were collected from long-term survivors at sacrifice for further in vitro immunological assessment. In 2 long-term survivors after repetitive AD-MSC treatment donor specific graft tolerance was challenged with a secondary BN skin graft.

\section{Chimerism and $\mathrm{T}_{\text {reg }}$ Analysis}

To detect chimerism in the peripheral blood, mouse antirat class I RT1Ac antibodies (AbD Serotec) were used for labeling donor cells ( $\mathrm{RT} 1^{\mathrm{n}}, \mathrm{BN}$ rats), and mouse anti-rat CD45Ra, CD11b/c, CD4, and CD8 antibodies (eBioscience) were used as markers of cell lineages. Cells were then analyzed using an LSRII flow cytometer and data was analyzed using FlowJo software.

Peripheral blood was routinely collected for analysis of peripheral chimerism and $\mathrm{T}_{\text {reg }}$ levels on POD 28. For $\mathrm{T}_{\text {reg }}$ analysis, red blood cells were lysed with erythrocyte lysing buffer (eBioscience, San Diego, CA) stained with various cell surface markers (fluorochrome-conjugated mouse anti-rat CD3, CD4, CD8, CD25, CD11b/c, CD45RA antibodies) or intracellular markers (fluorochrome-conjugated mouse anti-rat Foxp3 antibody), and then analyzed using an LSRII flow cytometer. Data were analyzed using FlowJo software.

\section{Mixed Lymphocyte Reaction Assays}

For $\mathrm{T}$ cell proliferation assays, peripheral blood mononuclear cells (PBMCs) $\left(2 \times 10^{5}\right.$ cells/well $)$ or $\mathrm{CD}^{+} \mathrm{CD} 25^{-}$ T cells $\left(\mathrm{T}_{\text {effs }}, 2 \times 10^{5}\right.$ cells/well) were isolated from the blood or spleens and lymph nodes of LEW naïve rats and long-term surviving hindlimb allograft recipient rats (AAA3 and AAA5, repetitive AD-MSC treatment) and cocultured in triplicates with irradiated (3000 rads) PBMCs or splenocytes $\left(5 \times 10^{4}\right.$ cells/well $)$ in 96 -well culture plates for 6 days. Stimulator PBMCs and splenocytes were isolated from the blood or spleens, respectively, of donor $\mathrm{BN}$ rats as well as thirdparty WF rats.

For $\mathrm{T}_{\text {reg }}$ immunosuppressive assays, naive LEW $\mathrm{T}_{\text {effs }}$ $\left(2 \times 10^{5}\right.$ cells/well $)$ were cocultured with flow-sorted $\mathrm{CD} 4{ }^{+} \mathrm{CD} 25^{\text {hi }} \mathrm{T}_{\text {reg }}$ from the spleens and lymph nodes of naïve, AAA3, and AAA5 LEW rats ( $T_{\text {eff }}$ to $T_{\text {reg }}$ ratio of 1:1, 2:1 and 4:1) in the presence of the irradiated BN or WF splenocytes $\left(5 \times 10^{4}\right.$ cells/well) for 6 days. The cells were pulsed with $\left[{ }^{3} \mathrm{H}\right]$ thymidine $(1 \mathrm{mCi} /$ well $)$ for the final 8 hours and $\left[{ }^{3} \mathrm{H}\right]$ thymidine incorporation was measured as counts per minute $(\mathrm{cpm})$ in a liquid scintillation counter (Perkin Elmer, USA).

\section{Histopathology}

Femoral arteries were harvested from the transplanted grafts at the endpoint. Samples were collected from longterm-surviving allografts in AD-MSC-treated animals on day 120 and rejecting controls (grades I and III). In addition, naive femoral artery samples were collected from $\mathrm{BN}$ rats. Samples were immediately fixed in Bouin's fixative (Ricca Chemical Company, Arlington, TX) for 24 hours. After fixation, samples were washed in PBS with lithium carbonate and incubated overnight in 5\% gelatin/sucrose. Samples were then cryopreserved in fresh gelatin/sucrose solution and 10$\mu \mathrm{m}$-thick sections were cut until all vessel wall layers were clearly exposed. Sections were washed in PBS at $37^{\circ} \mathrm{C}$ and incubated in $0.1 \mathrm{M}$ acetic acid solution $\left(37^{\circ} \mathrm{C}\right)$ to eliminate gelatin residues and washed again in PBS. Sections were stained for elastin. Samples were imaged with an Olympus Provis 1 microscope (Olympus America, Center Valley, PA) at $20 \times$ magnification. Tunica, intima, and media thickness in graft femoral arteries were measured using ImageJ (National Institute of Health, Bethesda, MD) as described previously. ${ }^{45}$ Intimal thickness was defined as (intima/[intima + media]) $\times$ 100 ; intima/media ratio as (intima/media) $\times 100$.

\section{Statistical Analysis}

InStat and Prism 5.0 software (GraphPad Software, La Jolla, CA) was used for statistical analysis. The data is presented as means \pm SD unless otherwise indicated. Differences between the groups were assessed by one-way ANOVA and Bonferroni multiple comparison posttest. Data showed normal distribution. Graft survival was compared between the different groups using Kaplan-Meier analysis. A value of $P$ less than 0.05 was chosen to represent statistical significance.

\section{RESULTS}

\section{ALS Conditioning Results in Temporary Leucocyte Depletion In Vivo}

Leucocyte counts significantly decreased in vivo, declining from $12.95 \pm 2.06$ to $2.78 \pm 1.65 \times 10^{3} / \mathrm{mL}$ within 24 hours after ALS administration (Figure 1). Levels remained significantly lower compared to baseline $(P<0.01$ baseline vs days 1,3 , and 6) for 6 days and showed significant recovery only after 10 days $\left(8.53 \pm 2.60 \times 10^{3} / \mathrm{mL}, P<0.05\right.$ vs day 1$)$.

\section{Multiple AD-MSC Administration Improves Allograft Survival Compared With Single Treatment}

All transplanted limbs were rejected in control animals within 7 weeks (Figure 2). All animals receiving singleadministration of AD-MSCs on POD 4 rejected within 8 weeks. In the group receiving single-administration of AD-MSCs on POD 1, $60 \%$ of recipients demonstrated graft survival over 12 weeks and $50 \%$ of the remaining grafts survived over 15 weeks. Repeated AD-MSC administration on

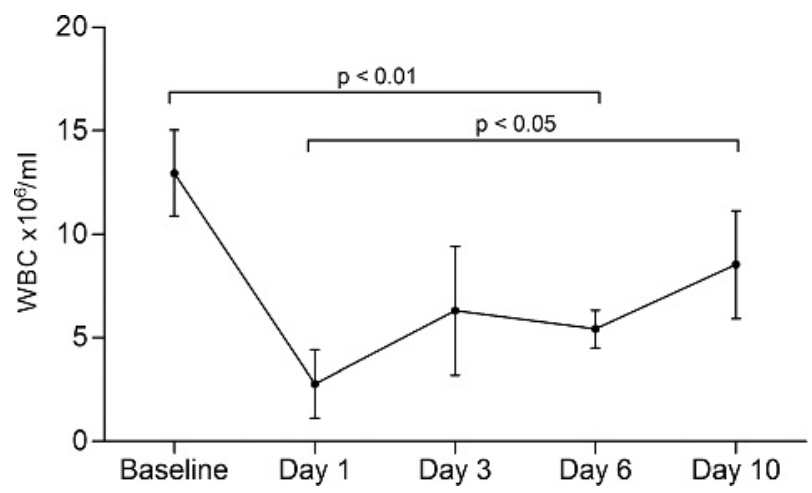

FIGURE 1. The effect of ALS on white blood cell (leucocyte) count. Leucocyte levels were analyzed in naive rats over 10 days after ALS administration. WBCs decreased significantly within 24 hours $(P<0.01)$ and only recovered slowly until reaching significantly increased levels on day $10(P<0.05$ vs day 1$)$. WBC, white blood cells. 


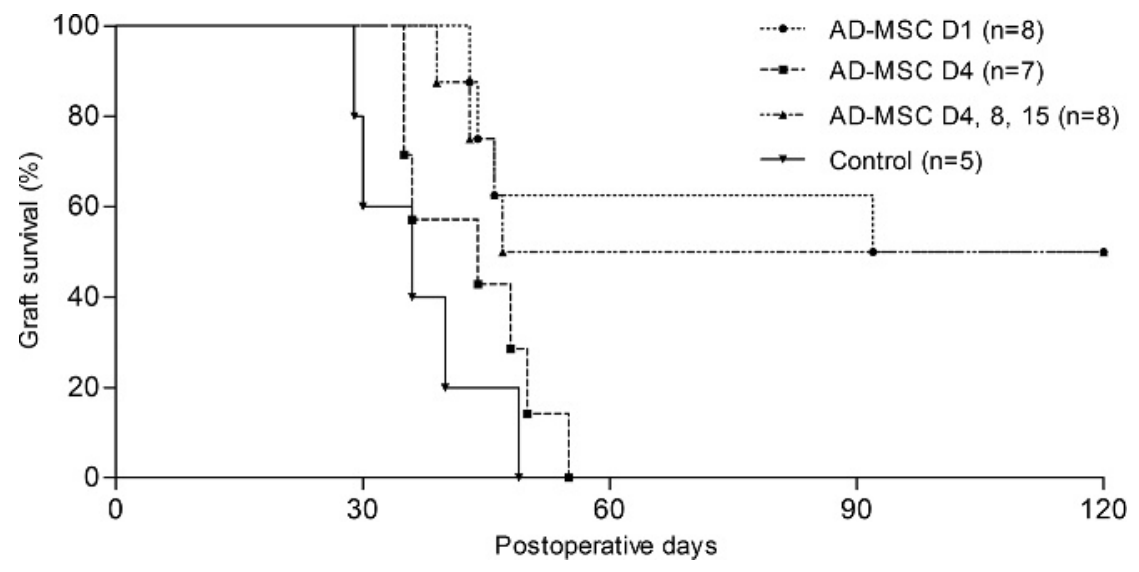

FIGURE 2. Kaplan-Meier survival curve for vascularized composite allograft survival. Controls and animals receiving single-shot AD-MSCs on POD 4 rejected completely within 7 to 8 weeks, whereas $50 \%$ of the allografts of animals receiving AD-MSCs on POD 1 or repeatedly on PODs 4,8 , and 15 survived longer than 120 days.

POD 4, 8, and 15 resulted in graft survival over 15 weeks in $50 \%$ recipients. Two animals in this group were investigated more in-depth (AAA3 and AAA5) for in vitro assessment of immune tolerance. Two other long-term survivors (AAA7 and AAA8) received secondary donor skin grafts to challenge donor specific graft tolerance. Recipient AAA7 (Figure 3) accepted the donor skin graft while recipient AAA8 rejected it. Donor skin grafting in AAA8 also triggered hindlimb allograft rejection and was eventually euthanized on day 150 after transplantation.
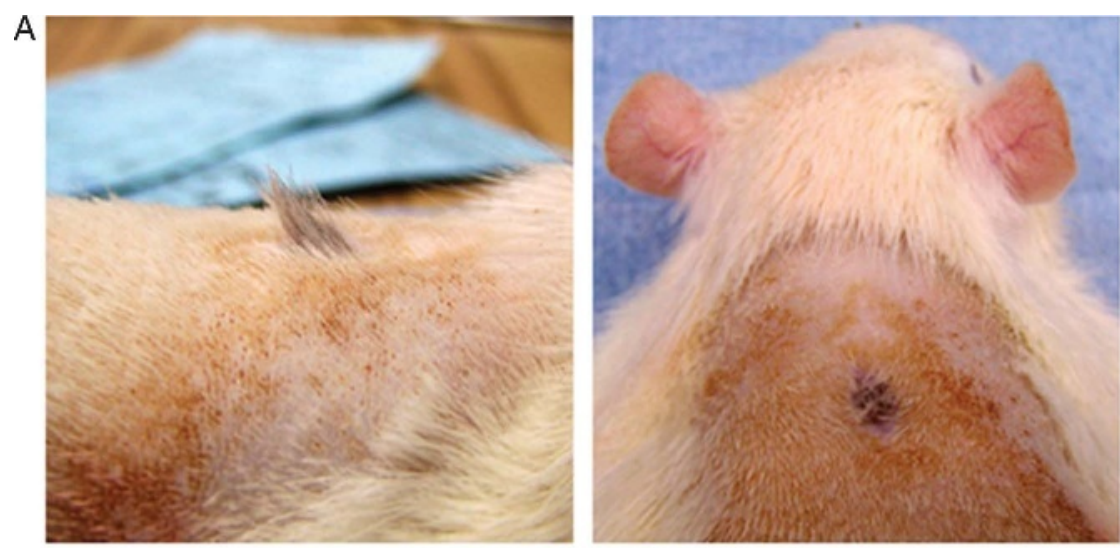

B
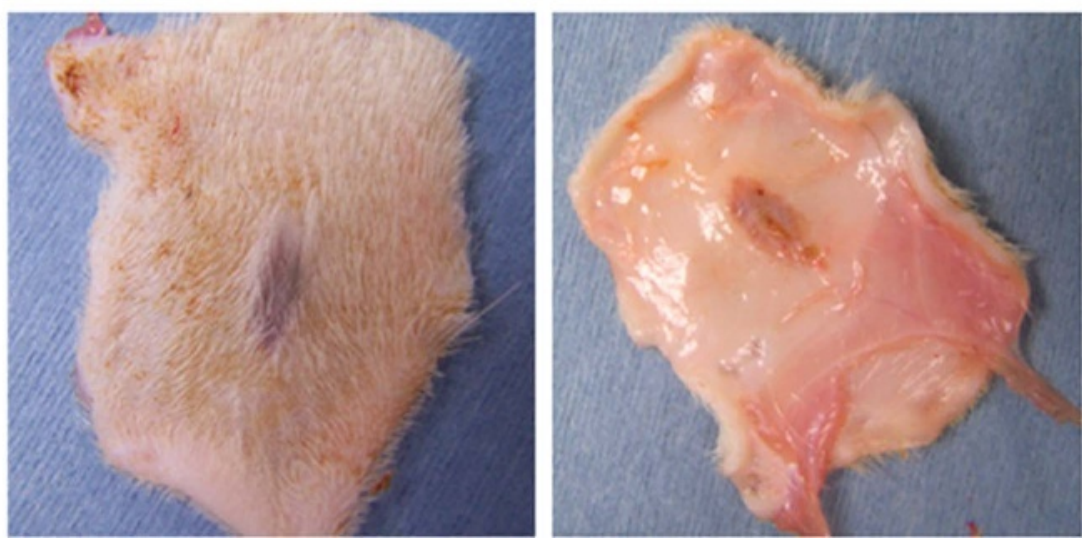

FIGURE 3. A, The skin graft (BN) transplanted onto recipient (LEW, AAA7) 120 days after hindlimb transplantation healed and was tolerated, showing growing brown hair. B, Harvested skin graft after animal euthanasia demonstrating the integrated and accepted BN skin graft. 

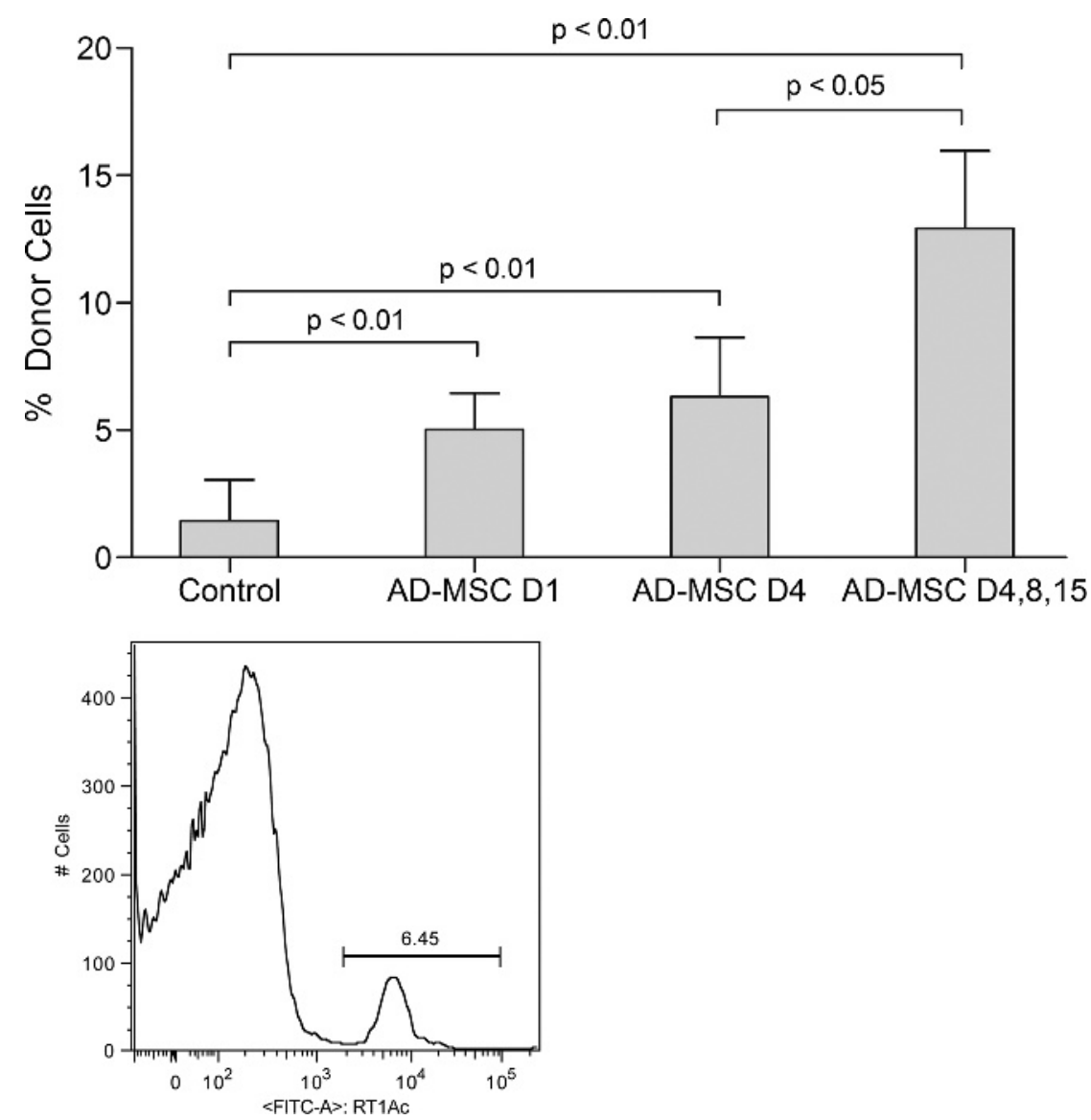

FIGURE 4. Peripheral blood chimerism. FACS results showing levels of class I (RT1Ac) chimerism in the peripheral blood 4 weeks after transplantation. Repetitive treatment with a cumulative dose of $3 \times 10^{6} \mathrm{AD}-\mathrm{MSC}$ showed the highest level of chimerism $(P<0.01 \mathrm{vs}$ control), while single treatment with $1 \times 10^{6} \mathrm{AD}-\mathrm{MSC}$ s showed significantly lower levels ( $P<0.05$ vs repetitive treatment). FACS, fluorescence-activated cell sorting.

controls; Figure 5). Repetitive AD-MSC treatment significantly increased $\mathrm{T}_{\text {reg }}$ levels to $17.8 \pm 9.8 \%$ compared with controls $(P<0.01)$ and single-shot treatment groups $(P<0.01$ vs day 1 and $P<0.05$ vs day 4). Although peripheral blood chimerism did not persist in long-term survivors at 17 weeks (Figure 6A), $\mathrm{T}_{\text {reg }}$ levels were significantly higher after repetitive treatment in AAA3 (6.4\%) and AAA5 $(4.5 \%)$ rats compared with naive controls $(2.2 \%$; Figure $6 \mathrm{~B})$.

\section{Repetitive AD-MSC Results in Suppressed T Cell Function In Vitro on Mixed Lymphocyte Reactivity Assay}

After stimulation by either irradiated donor (BN) or third party (WF) PBMCs, PBMCs from AAA3 and AAA5 rats exhibited lower proliferative responses compared with naive animals (naive $3685 \pm 387 \mathrm{cpm}$; AAA3 $2500 \pm 763$ and AAA5 $1340 \pm 350$ for BN-PBMCs; $P<0.001$ vs naive; naive $3974 \pm 528$, AAA3 $2023 \pm 642$ and AAA5 $1946 \pm 28 \mathrm{cpm}$ for WF-PBMC; $P<0.001$ vs naive; Figure 7). Flow-sorted $\mathrm{T}_{\text {effs }}$ from AAA3 and AAA5 rats, which did not contain $\mathrm{T}_{\text {reg }}$, exhibited a lower proliferation response $(39550 \pm 636$ and $23540 \pm 2938 \mathrm{cpm}$, respectively) than those from naive animals $(96380 \pm 13070 ; P<0.001)$ after being stimulated by donor (BN) antigen-presenting cells (APCs). Similar results were found after stimulation with third party (WF) APCs (naive $101448 \pm 11233 \mathrm{cpm}$; AAA3 $40648 \pm 922 \mathrm{cpm}$ and AAA5 $37263 \pm 5874 \mathrm{cpm} ; P<0.001$ vs naive) (Figure 8). $\mathrm{T}_{\text {reg }}$ from
AAA3 rats, but not AAA5 rats, markedly inhibited naïve $T_{\text {eff }}$ proliferation $(40390 \pm 1016[$ AAA3] vs $77350 \pm 1014$ [naive] cpm; $P<0.001)$ at a suppressor/responder ratio of 1:4 when stimulated by APC from Ag-specific donor (BN) rats, whereas no significant difference among groups was found using a suppressor/responder ratio of 1:1. Furthermore, no significant difference was found in the suppressive function of $\mathrm{T}_{\text {reg }}$ between naïve, AAA3, and AAA 5 rats when $\mathrm{T}_{\text {effs }}$ were stimulated by APCs from non-Ag-specific third party (WF) rats (Figure 9; $42000 \pm 5791$ vs $37440 \pm 3528$ vs $31890 \pm 1273 \mathrm{cpm}$, respectively; $P<0.05$ ).

\section{AD-MSC Treatment Suppresses Development of Chronic Graft Vasculopathy in Long-Term Survivors}

Compared with naive animals $(18.48 \pm 7.77 \%)$, the intimal thickness of rejected allografts was significantly increased $(42.87 \pm 6.9 \%$ [grade I] and $48.76 \pm 10.6 \%$ [grade III]; both $P<0.001)$. Rejected grafts showed a significantly higher intimal thickness than AD-MSC-treated long-term survivors $(17.06 \pm 9.2 \%, P<0.001$ vs grades I and III). Similar results were found for intima/media ratio; although rejecting animals revealed elevated values $(77.22 \pm 21.1 \%$ [grade I] and $82.33 \pm 21.8 \%$ [grade III]), nonrejecting AD-MSC animals showed significantly lower values $(21.82 \pm$ $15.01 \% ; P<0.001$ vs grades I and III), similar to naive 

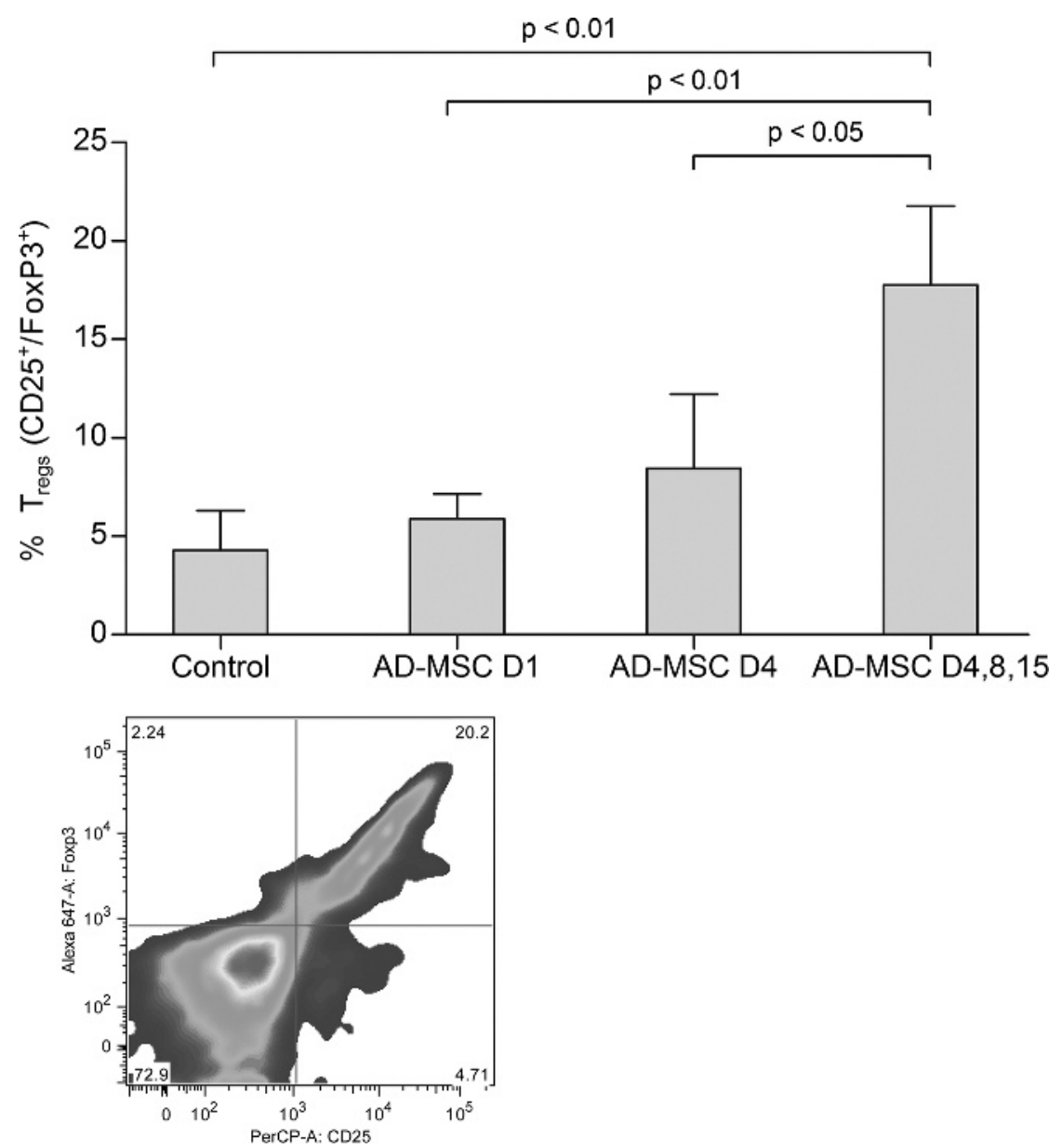

FIGURE 5. FACS results showing $\mathrm{T}_{\text {reg }}$ levels $\left(\mathrm{CD} 4^{+} \mathrm{CD} 25^{+} \mathrm{FoxP} 3^{+}\right)$at 4 weeks. Repetitive treatment with a cumulative dose of $3 \times 10^{6} \mathrm{AD}-\mathrm{MSCs}$ showed the highest level of $\mathrm{T}_{\text {reg }}$ generation ( $P<0.01 \mathrm{vs}$ control), whereas single treatment with $1 \times 10^{6} \mathrm{AD}-\mathrm{MSC}$ showed significantly lower levels (day $4 P<0.05$ and day $1 P<0.01$ vs repetitive treatment). Represented as percentage of $\mathrm{T}_{\text {reg }}\left(\mathrm{CD}^{2} 5^{+} \mathrm{FoxP} 3^{+}\right)$of the total $\mathrm{CD} 4^{+} \mathrm{T}$ cell population.

animals $(23.7 \pm 12.44 \% ; P<0.001$ vs grade I and III rejection; Figure 10).

\section{DISCUSSION}

Immunomodulatory strategies involving repetitive MSC administration have shown promise in small and large animal models. ${ }^{48,49}$ Graft survival seems to correlate with $\mathrm{T}_{\text {reg }}$ levels in experimental VCA. ${ }^{34,50}$ In our study, both the early single treatment and the repetitive AD-MSC administration strategies were able to significantly prolong allograft survival. However, analysis of $\mathrm{T}$ cell function and especially $\mathrm{T}_{\text {reg }}\left(\mathrm{CD} 4^{+} \mathrm{CD} 25^{\text {hi }} \mathrm{FoxP}^{+}\right)$modulation suggests a superior tolerogenic potential of the multidosing regimen. We found sustained higher levels of $\mathrm{T}_{\text {reg }}$ compared with controls, leading to long-term VCA acceptance.

The administered AD-MSCs were characterized by typical mesenchymal surface marker phenotypes $\left(\mathrm{CD} 29^{\mathrm{hi}} \mathrm{CD} 73^{\mathrm{hi}} \mathrm{CD} 90^{\mathrm{hi}} \mathrm{CD} 45^{-}\right.$) as described previously. ${ }^{40,51}$ As demonstrated earlier in in vitro studies by our group, ALS exposure leads to decreased viability, differentiation, and proliferation parameters of AD-MSCs at a clinically relevant dose range. Similar effects were seen with FK-506, rapamycin, and mycophenolic acid on MSCs. ${ }^{43,52}$ Other studies as by Buron et $\mathrm{al}^{44}$ have shown that immunosuppressive drugs can increase or antagonize the beneficial effects of MSC. For example, Cyclosporine (CsA) has shown lower toxicity compared to FK-506 in VCA in rodent and swine MSCbased protocols, as demonstrated by other groups. ${ }^{33,41,48}$ Therefore, selection of the appropriate conditioning regimen is of utmost importance when coupled with cell-based therapies to avoid negative collateral toxicity. Conditioning with irradiation or selective antibodies may serve as alternative conditioning regimens. ${ }^{41,53}$ Timing of cell therapy with respect to induction treatments is also crucial and needs to be adjusted to adequately prepare the recipient for transplantation, while avoiding drug toxicity to cells used concomitantly for immunomodulation.

Delayed administration of AD-MSCs on day 4 was associated with worse outcomes compared with day 1 injection. The reasons for this remain to be conclusively investigated in future studies, but we hypothesize as follows: The earliest reports on the in vivo effects of ALS on lymphocytes and hematopoietic stem cells confirm that ALS has cytotoxic and cytolytic effects. $^{54,55}$ The recipient alloresponse to the donor antigens and allosensitization occurs during the first few days after VCA. Cell surface coating and splenic removal mostly mediate the acute cytotoxic effects of ALS on lymphocytes. This may occur with MSC as well. However, the cytolytic effects of ALS are mediated by complement mediated cell lysis. 
A

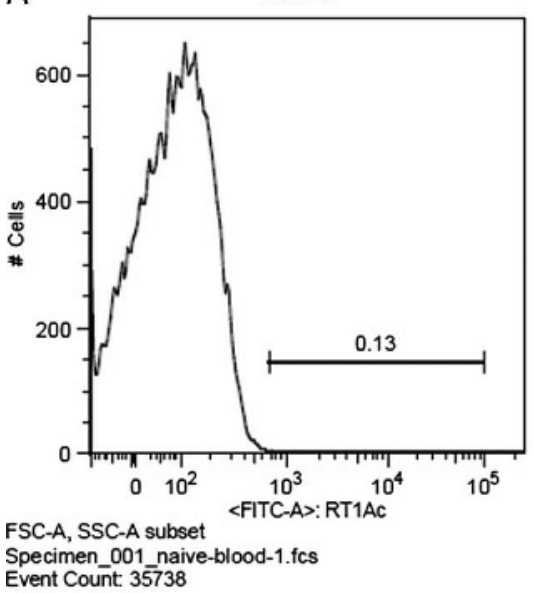

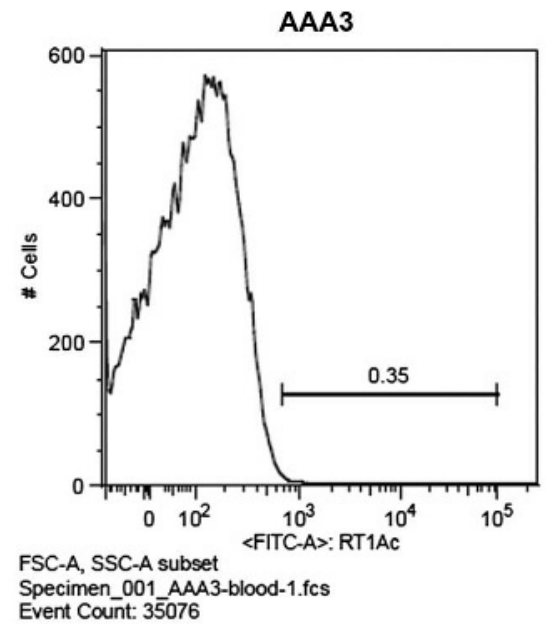

Specimen_001_AAA3
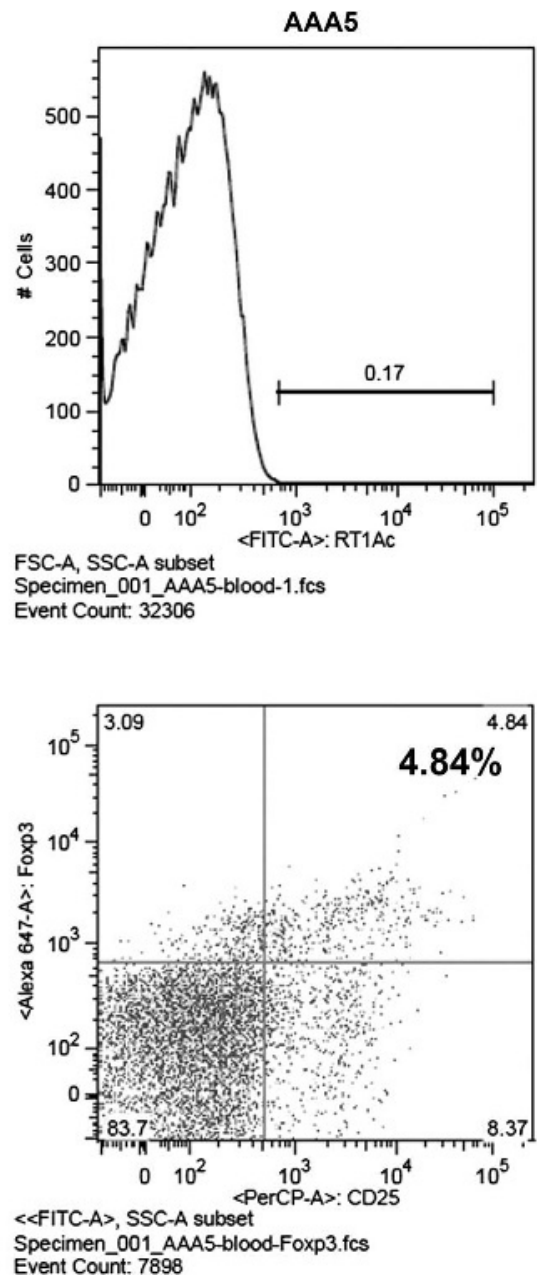

Event Count: $7 \overline{8} 98$

B

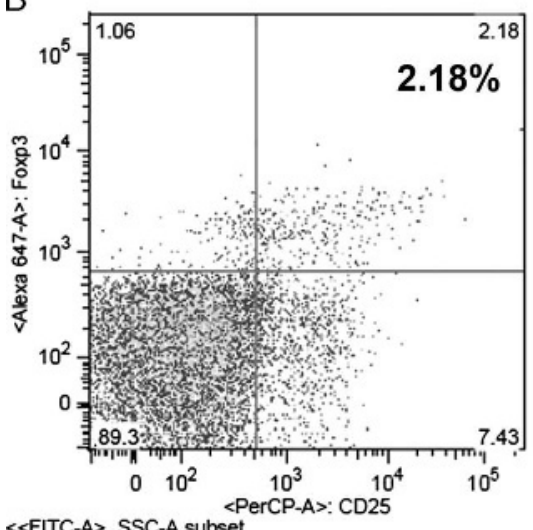

$\ll$ FITC-A>, SSC-A subset Specimen_001_naive-blood-Foxp3.fcs Event Count: 14049

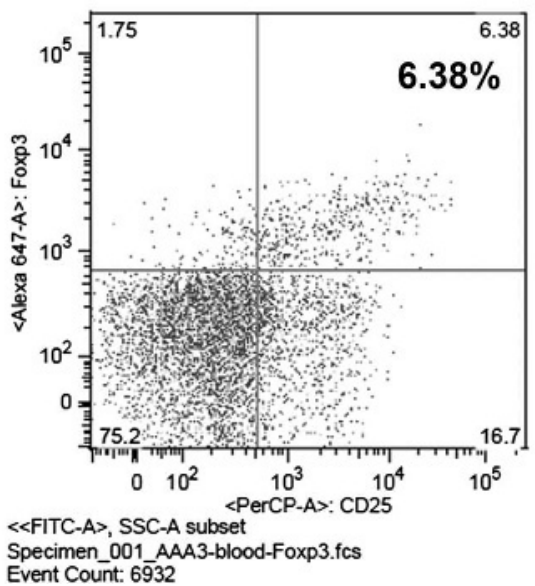

FIGURE 6. A, Peripheral blood chimerism in long-term graft recipients. Blood was collected from AAA 3 and AAA5 rats at POD 60 . No donor cell microchimerism could be detected at this time point. B, The percentages of $\mathrm{CD} 4^{+} \mathrm{CD} 25^{+} \mathrm{FoxP}^{+} \mathrm{T}_{\text {reg }}$ were elevated in peripheral blood from AAA3 (6.38\%) and AAA5 (4.84\%) rats compared with a naiive control (2.18\%).

Complement development in the recipient against donor antigens may take 24 to 72 hours to occur. ${ }^{56,57}$ Thus, MSCs administered on day 4 may be prone to both cytotoxic effects as well as complement-mediated lysis while those on day 1 may be relatively spared from the effects of complement. Cytotoxic and/or cytolytic effects of ALS may have variable deleterious influence on functional effects of MSC (homing, paracrine, or proliferation). ${ }^{58,59}$

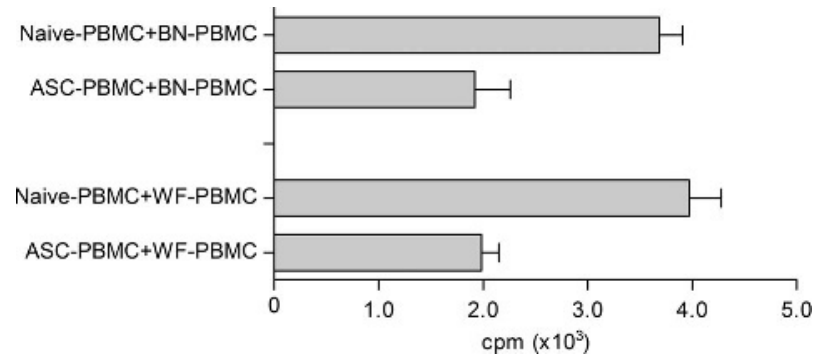

FIGURE 7. PBMCs from AAA 3 and AAA5 rats exhibited a lower proliferative response than PBMCs from naïve animals after being stimulated by irradiated allogenic PBMCs, either from same donor (BN) or from a third party (WF), suggesting an attenuated alloresponse in these 2 long-term tolerant animals.
Our findings indicate that in vitro effects of these drugs may not translate uniformly and equivocally into the in vivo setting. After ALS injection, lymphocyte counts were markedly depleted and slowly recovered, reaching baseline levels after almost 2 weeks. The repetitive AD-MSC administration protocol was aimed at establishing a sustained immunomodulatory effect during a permissive time window early after

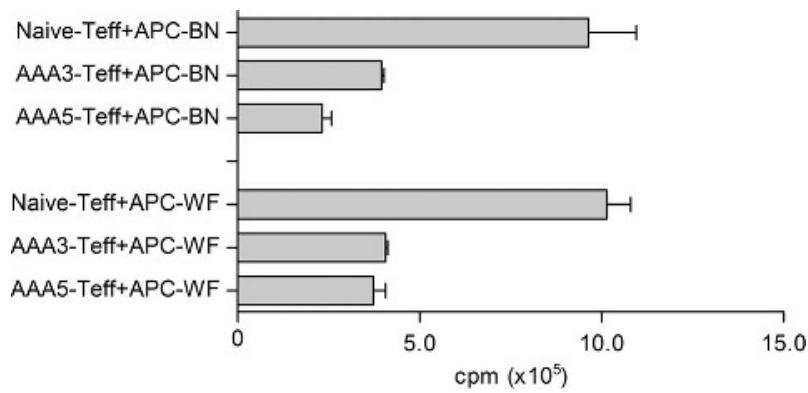

FIGURE 8. $T_{\text {effs }}$ from $A A A 3$ and $A A A 5$ rats exhibited a lower proliferative response than those from naiive animals after being stimulated by either same donor (BN) or third party (WF) antigen-presenting cells. This suggests that $T_{\text {effs }}$ from long-term graft survival animals showed a nonspecific and donor-independent reduced immune response to alloantigens even in the absence of $\mathrm{T}_{\text {reg }}$ suppression. 


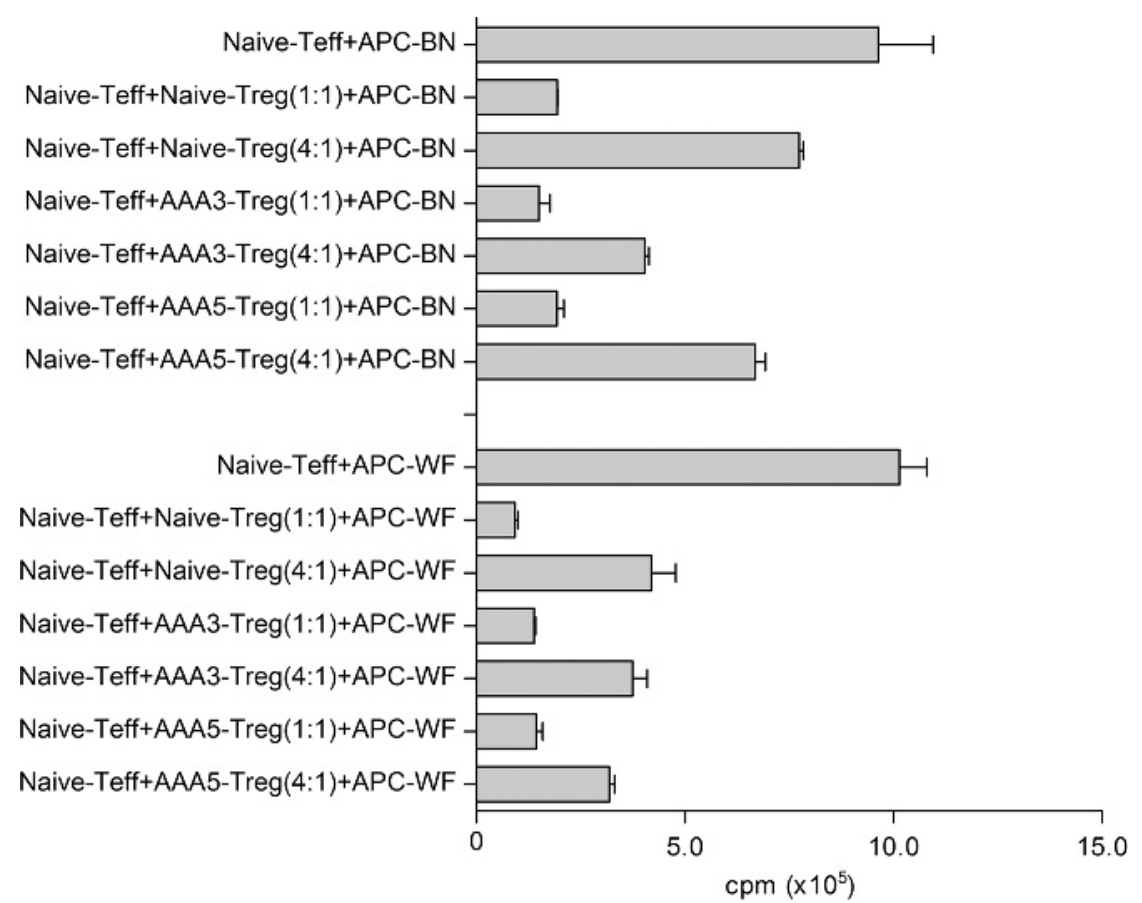

FIGURE 9. $T_{\text {reg }}$ from AAA3, AAA5, and naive animals all had markedly inhibited naive $T_{\text {eff }}$ proliferation, regardless of whether they were stimulated by antigen-presenting cells from Ag-specific BN rats or non-Ag-specific third party WF rats. These results demonstrate immunocompetent $\mathrm{T}_{\text {reg }}$ and suggest that $\mathrm{T}_{\text {reg }}$ suppressive function from a long-term allograft tolerant animal was unrelated to Ag-specific triggering.

transplantation. Upregulation of $\mathrm{T}_{\text {reg }}$ may be a temporary finding as found earlier in our own series. ${ }^{40}$ However, we speculate that additional AD-MSC administration at later timepoints may have potential to maintain higher $\mathrm{T}_{\text {reg }}$ levels and further improve outcomes.

Given the known cytotoxic ALS effects on AD-MSCs in vitro, repetitive dosing seems to be a successful strategy to overcome any potential in vivo collateral adverse effects on cell viability. Besides these effects, a "first-pass" effect of filtering organs might sequester MSCs after systemic injection and require higher cell doses and multiple administrations. ${ }^{60,61}$ In previous studies, we found that at least some of intravenously administered cells had homed to sites of tissue injury. ${ }^{58}$ It is not yet clear whether MSCs need to home to allografts or to recipient-donor interfaces for beneficial effects for tolerance induction. Furthermore, we found AD-MSCs to be significantly smaller than BM-MSCs, ${ }^{52}$ which might decrease organ entrapment and favor their homing to target tissues, which agrees with similar findings from Rider et al. ${ }^{62}$

Even though prolongation of elevated $\mathrm{T}_{\text {reg }}$ levels was observed, stable chimerism was not achieved in long-term tolerant animals. Some authors argue that stable mixed chimerism is a prerequisite for long-term donor-specific tolerance. ${ }^{63}$ Kuo and colleagues ${ }^{33}$ achieved long-term peripheral blood chimerism ( $>150$ days) after serial AD-MSC injections with increased $T_{\text {reg }}$ levels in peripheral blood and skin after 4 weeks, which eventually decreased to naïve levels later in a similar rodent VCA model as in this study. In contrast, in a more recent report, Cheng et $\mathrm{al}^{50}$ used syngeneic AD-MSCs and found a delayed $\mathrm{T}_{\text {reg }}$ increase starting later than 4 weeks postoperatively but remaining at high levels in the follow-up of long-term tolerant recipients. Their regimen used a single treatment of syngeneic AD-MSC injection, which achieved a slightly higher graft acceptance $(66 \%)$ as compared with our study, whereas Kuo and his group reached long-term graft survival in almost $90 \%$ of the animals following multiple injections. It remains to be investigated whether long-term tolerance can be achieved with sole AD-MSC treatment or if combination therapies with agents, such as hematopoietic cells or bone marrow, would be more effective either alone or in combination with AD-MSC. Preliminary data in clinical hematopoietic stem cell transplantation have provided some early clues that MSCs may be efficacious in facilitating engraftment or reestablishing functional bone marrow without graftversus-host disease. ${ }^{64}$

To our knowledge, this is the first study to assess in vitro $\mathrm{T}$ cell function in long-term VCA-tolerant animals after repetitive administration of AD-MSCs and correlation with $\mathrm{T}_{\text {reg }}$ activity in vivo. In general, we found no significant differences in $T_{\text {eff }}$ suppression by $T_{\text {reg }}$ from long-term tolerant animals when stimulated by donor-specific APCs compared to naïve $T_{\text {reg }}$, besides at a 4:1 effector/suppressor rate, where AAA3 rats showed a significantly higher suppressive function on $\mathrm{T}_{\text {effs. }}$. In all animals, we could demonstrate immunocompetent $T_{\text {reg }}$ as evidenced by clear modulation of the $T_{\text {eff }}$ response. There was no significant difference between $T_{\text {reg }}$ from naive animals and those from long-term animals when stimulated by third party (WF) APCs, which suggests donornon-specific $\mathrm{T}_{\text {reg }}$ function. $\mathrm{T}_{\text {effs }}$ from AAA3 and AAA5 animals showed a weaker immune response when stimulated ex vivo compared to naive $T_{\text {effs }}$, suggesting a different immunologic behavior after AD-MSC administration. This was confirmed by experiments on the immunoresponse of recipient PBMCs toward donor and third-party APCs. Again, 

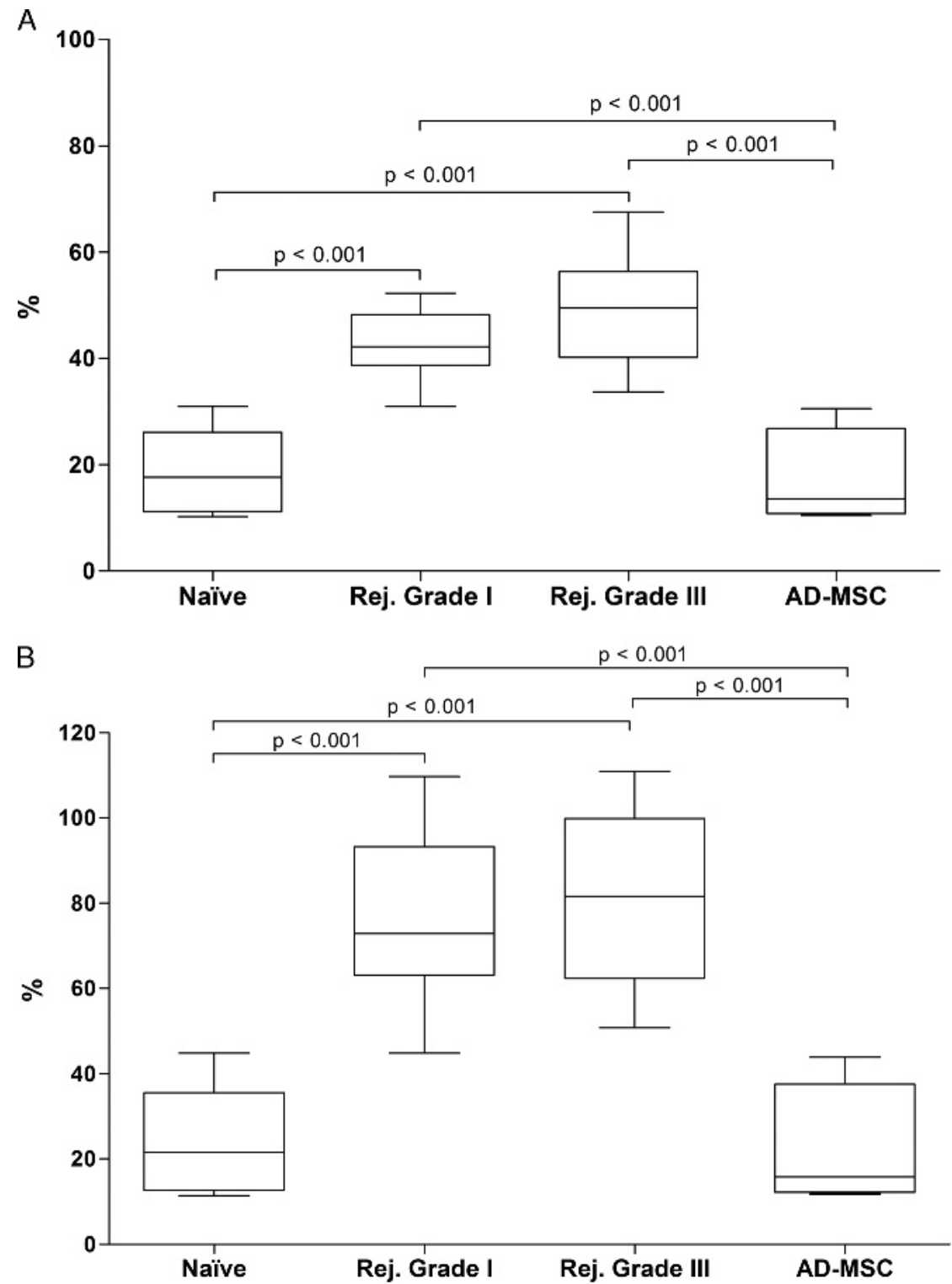

FIGURE 10. A, Although the intima thickness gradually increased during rejection, it was significantly reduced in the femoral artery of AD-MSC-treated recipients with long-term surviving allografts. The ratio is described as intima/intima + media thickness. B, Similarly, the intima/media ratio was significantly reduced after AD-MSC treatment, whereas rejection led to an increased ratio. Displayed as box plot (whiskers, 5-95\% percentile).

PBMCs from long-term survivors responded lesser than PBMCs from naive animals. A previous report showed that MSCs were able to alter T cell function from a proinflammatory to an anti-inflammatory phenotype in vitro. ${ }^{65}$ Another in vitro study reports the ability of human AD-MSCs to inhibit $\mathrm{T}$ cell responses and upregulate $\mathrm{T}_{\text {reg. }}{ }^{30-32}$ Our results concur with prior studies.

Secondary skin grafting in long-term tolerant animals resulted in abrogation of the tolerance state indicating that true or stable tolerance was not achieved. Although the mechanisms underlying this phenomenon are outside the scope of this study, it may be reasonable to conclude that AD-MSC-mediated immunomodulation resulted in prope-tolerance or a state of graft acceptance without immunosuppression.

Chronic GV is the sine-qua-non of chronic rejection across all solid organs including VCA. We identified significant differences in GV as estimated by intima-media thickness evaluation of the large femoral arteries between rejecting animals and AD-MSC-treated long-term survivors, with the latter revealing normal intima-media thickness, comparable to values of naïve arteries. Naive animals were compared to long-term surviving animals that had received AD-MSC treatment (day 1 and repetitive group). In those animals that did not undergo rejection, AD-MSC treatment was associated with absence of intimal hyperplasia. However, rejecting animals at different grades (grades I and III) from different groups uniformly showed pathological vascular changes. In addition to the split-rejection phenomenon observed solely in the skin component, we were able to demonstrate GV that occurred in animals with both lower grade (Banff I) as well as in animals with advanced rejection (Banff III). This may support the hypothesis that the skin may not be a true sentinel of chronic graft rejection, which is characterized by GV in the subdermal vasculature with minimal skin changes. 
As shown by our group, MSCs are capable of inducing vascular changes, such as neoarteriogenesis and remodeling. ${ }^{59}$ Other groups have reported that MSC treatment ameliorates inflammatory arterial intima thickening, such as during arteriosclerotic development ${ }^{66}$ or after VCA. ${ }^{67}$ The intimal thickness ratio was calculated based on measurements assessed by ultrasound investigation of the major graft arteries by Kückelhaus et $\mathrm{al}^{67}$ in a study that correlated GV with clinical outcomes in VCA grafts. Our study is the first, albeit pilot report on GV in large graft arteries (femoral vessels) and AD-MSC-mediated inhibition of GV in VCA. We intend to explore this finding conclusively in a larger study to identify AD-MSC-based strategies for inhibition or reversal of intimal hyperplasia in VCA.

Taken together, our in vitro results point to superior potential of repetitive AD-MSC administration compared to in vivo outcomes in VCA. The differential improvement or effect on graft survival across different time points as studied supports the potential for future studies into optimization of the AD-MSC therapy dosing and frequency, combination with other cell therapies (such as HSC or BM-MSC or dendritic cells) as well as selection of appropriate conditioning or maintenance drug regimens. Repetitive AD-MSC treatment, in conjunction with a selected conditioning regimen and short-term immunosuppression, may be a promising strategy to achieve long-term survival of VCA by its effects on $\mathrm{T}_{\text {reg }}$ upregulation, suppression of progression of $\mathrm{GV}$ and promoting an immunomodulatory graft milieu.

\section{ACKNOWLEDGMENTS}

The authors thank Chiaki Komatsu, Nataliya Kostereva, and Paolo M. Fanzio for technical support, Pia Fuchs for the histology staining, and Christine Heiner for editing this manuscript.

\section{REFERENCES}

1. Health Resources and Services Administration DoH, Human Services. Organ procurement and transplantation network. Final rule. Fed Regist. 2013;78:40033-40042.

2. Brandacher G, Lee WP, Schneeberger S. Minimizing immunosuppression in hand transplantation. Exp Rev Clin Immunol. 2012;8: 673-683; quiz 684.

3. Hautz T, Brandacher G, Zelger B, et al. Immunologic aspects and rejection in solid organ versus reconstructive transplantation. Transplant Proc. 2010;42:3347-3353.

4. Sarhane KA, Tuffaha SH, Broyles JM, et al. A critical analysis of rejection in vascularized composite allotransplantation: clinical, cellular and molecular aspects, current challenges, and novel concepts. Front Immunol. 2013:4:406.

5. Khalifian S, Brazio PS, Mohan R, et al. Facial transplantation: the first 9 years. Lancet. 2014.

6. Petruzzo P, Kanitakis J, Badet L, et al. Long-term follow-up in composite tissue allotransplantation: in-depth study of five (hand and face) recipients. Am J Transplant. 2011;11:808-816.

7. Petruzzo P, Lanzetta M, Dubernard JM, et al. The International Registry on Hand and Composite Tissue Transplantation. Transplantation. 2010;90: 1590-1594.

8. Dharancy S, Giral M, Tetaz R, et al. Adherence with immunosuppressive treatment after transplantation: results from the French trial PREDICT. Clin Transplant. 2012;26:E293-299.

9. Kanitakis J, Jullien D, Petruzzo P, et al. Clinicopathologic features of graft rejection of the first human hand allograft. Transplantation. 2003;76: 688-693.

10. Ravindra KV, Wu S, McKinney M, et al. Composite tissue allotransplantation: current challenges. Transplant Proc. 2009;41:3519-3528.

11. Jadlowiec CC, Taner T. Liver transplantation: current status and challenges. World J Gastroenterol. 2016;22:4438-4445.
12. Leonard DA, McGrouther DA, Kurtz JM, et al. Tolerance induction strategies in vascularized composite allotransplantation: mixed chimerism and novel developments. Clin Dev Immunol. 2012;2012:863264.

13. Doycheva I, Amer S, Watt KD. De novo malignancies after transplantation: risk and surveillance strategies. Med Clin North Am. 2016;100: 551-567.

14. Gorantla VS, Brandacher G, Schneeberger S, et al. Favoring the riskbenefit balance for upper extremity transplantation - the Pittsburgh Protocol. Hand Clin. 2011;27:511-520, ix-x.

15. Schneeberger S, Gorantla VS, Brandacher G, et al. Upper-extremity transplantation using a cell-based protocol to minimize immunosuppression. Ann Surg. 2013;257:345-351.

16. Schneeberger S, Landin L, Kaufmann C, et al. Alemtuzumab: key for minimization of maintenance immunosuppression in reconstructive transplantation? Transplant Proc. 2009;41:499-502.

17. Xu J, Wang D, Liu D, et al. Allogeneic mesenchymal stem cell treatment alleviates experimental and clinical Sjogren syndrome. Blood. 2012;120: 3142-3151.

18. Zappia E, Casazza S, Pedemonte E, et al. Mesenchymal stem cells ameliorate experimental autoimmune encephalomyelitis inducing T cell anergy. Blood. 2005;106:1755-1761.

19. El-Jawhari JJ, El-Sherbiny YM, Jones EA, et al. Mesenchymal stem cells, autoimmunity and rheumatoid arthritis. QJM. 2014;107:505-14.

20. Obermajer N, Popp FC, Johnson CL, et al. Rationale and prospects of mesenchymal stem cell therapy for liver transplantation. Curr Opin Organ Transplant. 2014;19:60-64.

21. Popp FC, Eggenhofer E, Renner P, et al. Mesenchymal stem cells can induce long-term acceptance of solid organ allografts in synergy with lowdose mycophenolate. Transpl Immunol. 2008;20:55-60.

22. Keating A. Mesenchymal stromal cells: new directions. Cell Stem Cell. 2012;10:709-716.

23. Parekkadan B, Milwid JM. Mesenchymal stem cells as therapeutics. Annu Rev Biomed Eng. 2010;12:87-117.

24. Yagi H, Soto-Gutierrez A, Parekkadan B, et al. Mesenchymal stem cells: mechanisms of immunomodulation and homing. Cell Transplant. 2010; 19:667-679.

25. Lalu MM, Mclntyre L, Pugliese C, et al. Safety of cell therapy with mesenchymal stromal cells (SafeCell): a systematic review and meta-analysis of clinical trials. PLoS One. 2012;7:e47559.

26. Wang S, Qu X, Zhao RC. Clinical applications of mesenchymal stem cells. J Hematol Oncol. 2012;5:19.

27. English K. Mechanisms of mesenchymal stromal cell immunomodulation. Immunol Cell Biol. 2012.

28. Doorn J, Moll G, Blanc K, et al. Therapeutic applications of mesenchymal stromal cells: paracrine effects and potential improvements. Tissue Eng Part B Rev. 2012:18:101-115.

29. Caplan Al, Correa D. The MSC: an injury drugstore. Cell Stem Cell. 2011; 9:11-15.

30. Krampera M, Glennie S, Dyson J, et al. Bone marrow mesenchymal stem cells inhibit the response of naive and memory antigen-specific T cells to their cognate peptide. Blood. 2003;101:3722-3729.

31. Gonzalez-Rey E, Gonzalez MA, Varela N, et al. Human adipose-derived mesenchymal stem cells reduce inflammatory and Tcell responses and induce regulatory T cells in vitro in rheumatoid arthritis. Ann Rheum Dis 2010;69:241-248.

32. Ye Z, Wang Y, Xie HY, et al. Immunosuppressive effects of rat mesenchymal stem cells: involvement of CD4 + CD25+ regulatory T cells Hepatobiliary Pancreat Dis Int. 2008;7:608-614.

33. Kuo YR, Chen CC, Goto S, et al. Modulation of immune response and $T$ cell regulation by donor adipose-derived stem cells in a rodent hind-limb allotransplant model. Plast Reconstr Surg. 2011;128: 661e-672e.

34. Kuo YR, Chen CC, Shih HS, et al. Prolongation of composite tissue allotransplant survival by treatment with bone marrow mesenchymal stem cells is correlated with T cell regulation in a swine hind-limb model. Plast Reconstr Surg. 2011;127:569-579.

35. Ugarte DA, Morizono K, Elbarbary A, et al. Comparison of multi-lineage cells from human adipose tissue and bone marrow. Cells Tissues Organs. 2003;174:101-109.

36. Minteer D, Marra KG, Rubin JP. Adipose-derived mesenchymal stem cells: biology and potential applications. Adv Biochem Eng Biotechnol. 2013;129:59-71.

37. Cui L, Yin S, Liu W, et al. Expanded adipose-derived stem cells suppress mixed lymphocyte reaction by secretion of prostaglandin E2. Tissue Eng. 2007;13:1185-1195. 
38. Engela AU, Baan CC, Dor FJ, et al. On the interactions between mesenchymal stem cells and regulatory T cells for immunomodulation in transplantation. Front Immunol. 2012;3:126.

39. Melief SM, Zwaginga JJ, Fibbe WE, et al. Adipose tissue-derived multipotent stromal cells have a higher immunomodulatory capacity than their bone marrow-derived counterparts. Stem Cell Transl Med. 2013;2:455-463.

40. Plock JA, Schnider JT, Zhang W, et al. Adipose- and bone marrowderived mesenchymal stem cells prolong graft survival in vascularized composite allotransplantation. Transplantation. 2015;99:1765-1773.

41. Huang WC, Liao SK, Wallace CG, et al. Greater efficacy of tolerance induction with cyclosporine versus tacrolimus in composite tissue allotransplants with less myeloablative conditioning. Plast Reconstr Surg. 2011;127:1141-1148.

42. Eggenhofer $E$, Renner $P$, Soeder $Y$, et al. Features of synergism between mesenchymal stem cells and immunosuppressive drugs in a murine heart transplantation model. Transplant Immunol. 2011;25:141-147.

43. Hoogduijn MJ, Crop MJ, Korevaar SS, et al. Susceptibility of human mesenchymal stem cells to tacrolimus, mycophenolic acid, and rapamycin. Transplantation. 2008;86:1283-1291.

44. Buron F, Perrin H, Malcus C, et al. Human mesenchymal stem cells and immunosuppressive drug interactions in allogeneic responses: an in vitro study using human cells. Transplant Proc. 2009;41:3347-3352.

45. Unadkat JV, Schneeberger S, Horibe EH, et al. Composite tissue vasculopathy and degeneration following multiple episodes of acute rejection in reconstructive transplantation. Am J Transplant. 2010;10:251-261.

46. Sucher R, Oberhuber R, Rumberg G, et al. A rapid vascular anastomosis technique for hind-limb transplantation in rats. Plast Reconstr Surg. 2010; 126:869-874.

47. Sacks JM, Kuo YR, Taieb A, et al. Prolongation of composite tissue allograft survival by immature recipient dendritic cells pulsed with donor antigen and transient low-dose immunosuppression. Plast Reconstr Surg. 2008;121:37-49.

48. Kuo YR, Goto S, Shih HS, et al. Mesenchymal stem cells prolong composite tissue allotransplant survival in a swine model. Transplantation. 2009;87:1769-1777.

49. Kuo YR, Chen CC, Goto S, et al. Immunomodulatory effects of bone marrow-derived mesenchymal stem cells in a swine hemi-facial allotransplantation model. PLoS One. 2012; 7:e35459.

50. Cheng HY, Ghetu N, Huang WC, et al. Syngeneic adipose-derived stem cells with short-term immunosuppression induce vascularized composite allotransplantation tolerance in rats. Cytotherapy. 2014;16:369-380.

51. Schaffler A, Buchler C. Concise review: adipose tissue-derived stromal cells-basic and clinical implications for novel cell-based therapies. Stem Cells. 2007;25:818-827.

52. Tsuji WSJ, McLaughlin M, Schweizer R, et al. Effects of immunosuppressive drugs influence on viability and susceptibility of adipose and bone marrow-derived mesenchymal stem cells. Front Immunol. 2015.
53. Wachtman GS, Wimmers EG, Gorantla VS, et al. Biologics and donor bone marrow cells for targeted immunomodulation in vascularized composite allotransplantation: a translational trial in swine. Transplant Proc. 2011;43:3541-3544.

54. DeMeester TR. Mode of action of antilymphocyte serum. Surg Gynecol Obstet. 1969;129:717-722.

55. De Meester TR, Anderson ND. The potential bone marrow toxicity of antilymphocyte serum in mice. J Surg Res. 1968;8:192-195.

56. Wasowska BA, Lee CY, Halushka MK, et al. New concepts of complement in allorecognition and graft rejection. Cell Immunol. 2007; 248:18-30.

57. Mason JC, Yarwood H, Sugars K, et al. Induction of decay-accelerating factor by cytokines or the membrane-attack complex protects vascular endothelial cells against complement deposition. Blood. 1999;94:1673-1682.

58. Schlosser S, Dennler C, Eberli D, Schweizer R. Paracrine effects of mesenchymal stem cells enhance vascular regeneration in ischemic murine skin.Microvascular. 2012.

59. Schweizer R, Kamat P, Schweizer D, et al. Bone marrow-derived mesenchymal stromal cells improve vascular regeneration and reduce leukocyteendothelium activation in critical ischemic murine skin in a dose-dependent manner. Cytotherapy. 2014.

60. Plock JA, Schnider JT, Schweizer R, et al. Are cultured mesenchymal stromal cells an option for immunomodulation in transplantation? Front Immunol. 2013:4:41.

61. Eggenhofer E, Benseler V, Kroemer A, et al. Mesenchymal stem cells are short-lived and do not migrate beyond the lungs after intravenous infusion. Front Immunol. 2012;3:297.

62. Rider DA, Dombrowski C, Sawyer AA, et al. Autocrine fibroblast growth factor 2 increases the multipotentiality of human adipose-derived mesenchymal stem cells. Stem Cells. 2008:26:1598-1608.

63. Siemionow MZ, Izycki DM, Zielinski M. Donor-specific tolerance in fully major histocompatibility major histocompatibility complexmismatched limb allograft transplants under an anti-alphabeta T cell receptor monoclonal antibody and cyclosporine A protocol. Transplantation. 2003;76:1662-1668.

64. Lazarus HM, Koc ON, Devine SM, et al. Cotransplantation of HLAidentical sibling culture-expanded mesenchymal stem cells and hematopoietic stem cells in hematologic malignancy patients. Blol Blood Marrow Transplant. 2005;11:389-398.

65. Aggarwal S, Pittenger MF. Human mesenchymal stem cells modulate allogeneic immune cell responses. Blood. 2005;105:1815-1822.

66. Abdel-Kawi SH, Hashem KS. Possible therapeutic effect of stem cell in atherosclerosis in albino rats. A histological and immunohistochemical study. Int J Stem Cells. 2015;8:200-208.

67. Kueckelhaus M, Imanzadeh A, Fischer S, et al. Noninvasive monitoring of immune rejection in face transplant recipients. Plast Reconstr Surg. 2015; 136:1082-1089. 